\title{
Selecting Public Cultural Service Supply Mode with AHP and Game Theory
}

\author{
Juan $\mathrm{Li}^{*}$, Likun Cai and Ruiqi Song
}

Hebei United University, Shijiazhuang, Hebei, P. R. China

\begin{abstract}
This paper takes the major factors on supply of public cultural services such as profit gains, policy support, branding and social stability into consideration, and evaluates the importance of public cultural service supply in the government, enterprise and the third sector with Analytic Hierarchy Process model (AHP model). Furthermore, based on evolutionary game analysis and game theory, it determines that the optimal public cultural services model is supplied by the government and enterprises, and puts forward specific measures and suggestions.
\end{abstract}

Keywords: Analytic hierarchy process, evolutionary game analysis, game theory.

\section{INTRODUCTION}

With the economic development, people's living standards is rising, and the demand for public cultural services is also increasing. The importance of public cultural services for the construction of an advanced socialist culture has attracted more government attention. The Communist Party's 17th National Congress set "building a public cultural service system which could cover the whole society" as one of the important goals to achieve a comprehensive well-off society. Then, the Communist Party's 18th National Congress proposed to improve the public cultural service system, promote the effectiveness of public cultural services and basically completed the modernization of public cultural service system until 2020 [1].

As an important component of public cultural service system, the public cultural services supply plays a decisive role in the overall level of public cultural services. The nonexclusive, non-competitive and durable external effects and other features that public cultural services have obtained for public good, determine that the supply of public cultural services need government intervention [2]. However, only depending on a single supply mode i.e. the government, will inevitably lead to poor efficiency of public cultural service and unsupervised ending due to lack of competition. That is to say that the people of public cultural services could not meet the public's needs. Therefore, it needs to learn from the foreign supply mode and change the situation of only depending on government supply [3].

Research on the supply of public cultural services mainly focuses on two aspects: first, the public cultural services have distinctive characters of educational and social welfare [4]. The government should play a leading role in the public cultural service process. Second, we can learn from the western

\footnotetext{
*Address correspondence to these authors at the Hebei United University, Shijiazhuang, Hebei, P. R. China; Tel: 18986139113; E-mails: lijuanzw@126.com,shashatian01@qq.com
}

successful experience, which encourages all sectors active involvement to form a diversified supply mode. Both the aspects are mainly based on the experience of cultural theory researchers or managers, which lack practical foundation and convincingness. This paper analyses and selects the optimal supply of public cultural service mode with AHP method and game theory [5].

\section{ESTABLISHING AHP MODEL}

\subsection{Establishment of Hierarchical Structure}

Government, enterprise and third sector are the major supply departments of public cultural services. So that this paper studies the important degree of supply method among the three sectors through AHP. Public cultural service supply is quantified with AHP. Then this paper establishes the relationships among target layer, criterion layer, and scheme layer [6].

Target layer: the supply of public cultural services.

Criterion Layer: influence factors of scheme, $d_{1}$ is profit gains, $d_{2}$ is policy support, $d_{3}$ is brand and prestige, $d_{4}$ is social stability.

Program layer $[7,8]: B_{1}$ is the government supply, $B_{2}$ is enterprises supply, $B_{3}$ is the third sector supply, hierarchical structure is shown in Fig. (1):

\subsection{Constructing the Judgment (Pairwise Comparisons) Matrix}

Setting the reference scale of 1 to 9 , pairwise comparison matrices are obtained, judgment matrix is analyzed in Tables 1-5.

\subsection{Hierarchy Single Sorting and Consistency Test}

Tested with a consistency index:

$$
C I=\frac{\lambda_{\max }-n}{n-1} \cdot \lambda_{\max }
$$


is the largest eigenvalues of the comparison matrix, $n$ is the order of the comparison matrix. The smaller $C I$ is the judgment matrix that becomes closer to the same.

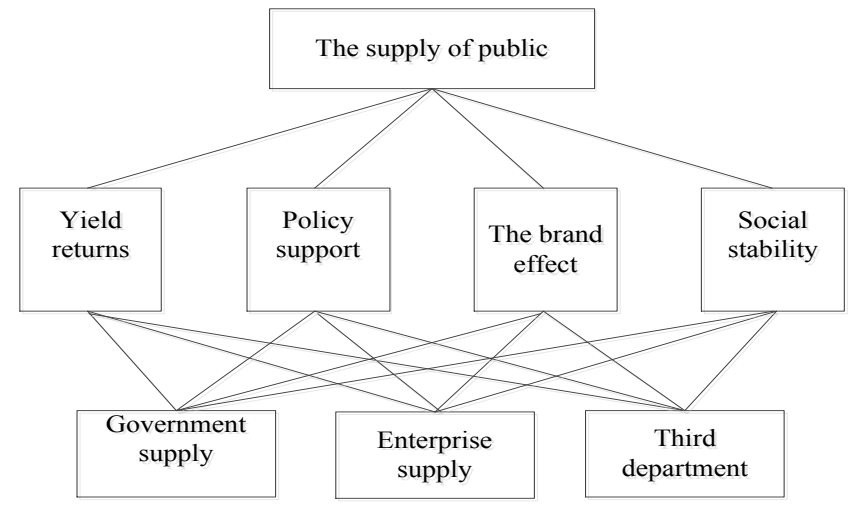

Fig. (1). Hierarchical structure of public cultural service supply.

Table 1. Comparison matrix.

\begin{tabular}{|c|c|c|c|c|}
\hline $\mathbf{G}$ & $d_{1}$ & $d_{2}$ & $d_{3}$ & $d_{4}$ \\
\hline \hline$d_{1}$ & 1 & $1 / 3$ & 3 & 3 \\
\hline$d_{2}$ & $31 / 8$ & 1 & 5 & 5 \\
\hline$d_{3}$ & $1 / 3$ & $1 / 5$ & 1 & 1 \\
\hline$d_{4}$ & $1 / 3$ & $1 / 5$ & 1 & 1 \\
\hline
\end{tabular}

Table 2. Comparison matrix.

\begin{tabular}{|c|c|c|c|}
\hline$d_{1}$ & $B_{1}$ & $B_{2}$ & $B_{3}$ \\
\hline \hline$B_{1}$ & 1 & 1 & $1 / 3$ \\
\hline$B_{2}$ & 1 & 1 & $1 / 3$ \\
\hline$B_{3}$ & 3 & 3 & 1 \\
\hline
\end{tabular}

Table 3. Comparison matrix.

\begin{tabular}{|c|c|c|c|}
\hline$d_{2}$ & $B_{1}$ & $B_{2}$ & $B_{3}$ \\
\hline \hline$B_{1}$ & 1 & 5 & 5 \\
\hline$B_{2}$ & $1 / 5$ & 1 & 5 \\
\hline$B_{3}$ & $1 / 5$ & $1 / 5$ & 1 \\
\hline
\end{tabular}

Table 4. Comparison matrix.

\begin{tabular}{|c|c|c|c|}
\hline$d_{3}$ & $B_{1}$ & $B_{2}$ & $B_{3}$ \\
\hline \hline$B_{1}$ & 1 & 5 & 8 \\
\hline$B_{2}$ & $1 / 5$ & 1 & 5 \\
\hline$B_{3}$ & $1 / 8$ & $1 / 5$ & 1 \\
\hline
\end{tabular}

Table 5. Comparison matrix.

\begin{tabular}{|c|c|c|c|}
\hline$d_{4}$ & $B_{1}$ & $B_{2}$ & $B_{3}$ \\
\hline \hline$B_{1}$ & 1 & 5 & 8 \\
\hline$B_{2}$ & $1 / 5$ & 1 & 5 \\
\hline$B_{3}$ & $1 / 8$ & $1 / 5$ & 1 \\
\hline
\end{tabular}

\subsection{The Total Sequencing and Consistency Test}

$$
B=\left\{\begin{array}{cccc}
1 & 1 / 3 & 3 & 3 \\
3 & 1 & 5 & 5 \\
1 / 3 & 1 / 5 & 1 & 1 \\
1 / 3 & 1 / 5 & 1 & 1
\end{array}\right\}
$$

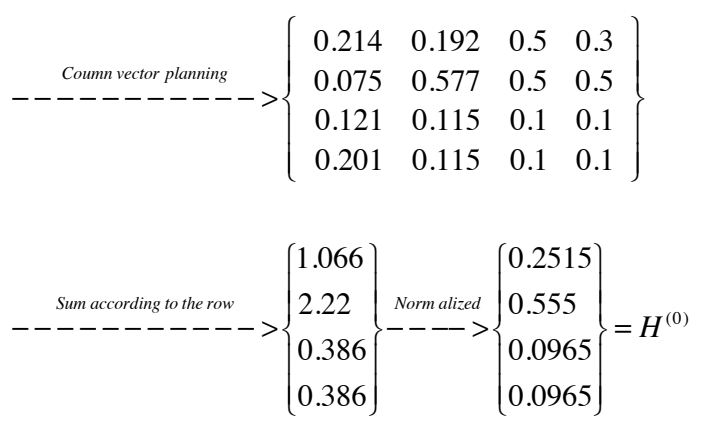

$B H^{(0)}=\left\{\begin{array}{cccc}1 & 1 / 3 & 3 & 3 \\ 3 & 1 & 5 & 5 \\ 1 / 3 & 1 / 5 & 1 & 1 \\ 1 / 3 & 1 / 5 & 1 & 1\end{array}\right\}\left\{\begin{array}{l}0.2514 \\ 0.5550 \\ 0.0965 \\ 0.0965\end{array}\right\}=\left\{\begin{array}{l}1.012 \\ 2.275 \\ 0.387 \\ 0.387\end{array}\right\}$

$\lambda_{\max }^{(0)}=\frac{1}{4}\left(\frac{1.012}{0.251}+\frac{2.275}{0.555}+\frac{0.387}{0.0965}+\frac{0.387}{0.0965}\right)=4.01$

$h^{(0)}=\left(\begin{array}{l}0.248 \\ 0.552 \\ 0.100 \\ 0.100\end{array}\right)$

Judgment matrix is

$C_{1}=\left(\begin{array}{ccc}1 & 1 & 1 / 3 \\ 1 & 1 & 1 / 3 \\ 3 & 3 & 1\end{array}\right), C_{2}=\left(\begin{array}{ccc}1 & 5 & 5 \\ 1 / 5 & 1 & 1 / 5 \\ 1 / 5 & 1 / 5 & 1\end{array}\right)$,

$C_{3}=\left(\begin{array}{ccc}1 & 5 & 8 \\ 1 / 5 & 1 & 5 \\ 1 / 8 & 1 / 5 & 1\end{array}\right), C_{4}=\left(\begin{array}{ccc}1 & 5 & 8 \\ 1 / 5 & 1 & 5 \\ 1 / 8 & 1 / 5 & 1\end{array}\right)$

Corresponding to the maximum eigenvalue and eigenvector are shown as follows in Table 6 : 
Table 6. RI values.

\begin{tabular}{|c|c|c|c|c|c|c|c|c|c|c|c|}
\hline $\mathbf{n}$ & $\mathbf{1}$ & $\mathbf{2}$ & $\mathbf{3}$ & $\mathbf{4}$ & $\mathbf{5}$ & $\mathbf{6}$ & $\mathbf{7}$ & $\mathbf{8}$ & $\mathbf{9}$ & $\mathbf{1 0}$ & $\mathbf{1 1}$ \\
\hline \hline $\mathrm{RI}$ & 0 & 0 & 0.58 & 0.90 & 1.12 & 1.24 & 1.32 & 1.41 & 1.45 & 1.49 & 1.51 \\
\hline
\end{tabular}

$\lambda_{\max }^{(1)}=3.62, h_{1}^{(1)}=\left(\begin{array}{l}0.244 \\ 0.244 \\ 0.512\end{array}\right)$

$\lambda_{\max }^{(2)}=3.31, h_{2}^{(1)}=\left(\begin{array}{l}0.657 \\ 0.251 \\ 0.092\end{array}\right)$

$\lambda_{\text {max }}^{(3)}=3.29, h_{3}^{(1)}=\left(\begin{array}{l}0.648 \\ 0.204 \\ 0.148\end{array}\right)$

$\lambda_{\max }^{(4)}=3.33, h_{4}^{(1)}=\left(\begin{array}{l}0.648 \\ 0.204 \\ 0.148\end{array}\right)$

Tested with consistency index:

$C I=\frac{\lambda_{\max }-n}{n-1}$

For the judgment matrix A,

$\lambda_{\max }^{(0)}=4.063, R I=0.9$

$C I=\frac{4.063-4}{4-1}=0.021$

$C R=\frac{C I}{R I}=\frac{0.021}{0.90}=0.023<0.1$

represents the degree of inconsistency of B is in the allowable range. At this time, the weight vector of $\mathrm{B}$ could be replaced by its feature vector.

Similarly, for the judgment matrix $C_{1}, C_{2}, C_{3}, C_{4}$ have passed conformance testing using the principles mentioned above. Therefore, the calculation from the target layer to scheme layer is shown in Fig. (2).

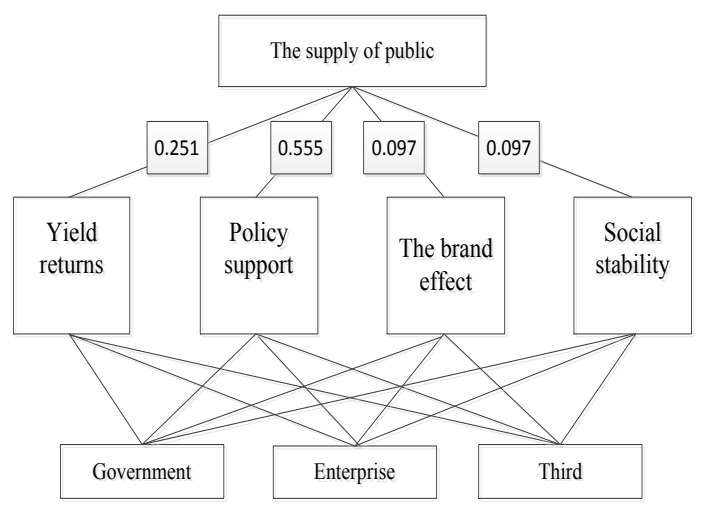

Fig. (2). Hierarchical structure.
Computing structure is as follows:

$h^{(1)}=\left(h_{1}^{(1)}, h_{21}^{(1)}, h_{3}^{(1)}, h_{4}^{(1)}\right)=$

$\left\{\begin{array}{llll}0.624 & 0.185 & 0.252 & 0.575 \\ 0.234 & 0.240 & 0.089 & 0.286 \\ 0.136 & 0.575 & 0.660 & 0.139\end{array}\right\}$

$h=h^{(1)} h^{(0)}=\left\{\begin{array}{llll}0.252 & 0.575 & 0.624 & 0.185 \\ 0.089 & 0.286 & 0.240 & 0.240 \\ 0.660 & 0.139 & 0.136 & 0.575\end{array}\right\}$

$\left\{\begin{array}{l}0.577 \\ 0.066 \\ 0.124 \\ 0.253\end{array}\right\}=\left\{\begin{array}{l}0.501 \\ 0.312 \\ 0.187\end{array}\right\}$

\section{THE GAME ANALYSIS ON PUBLIC CULTURAL SERVICE SUPPLY MODEL}

By the hierarchical analysis, it could be concluded that government and enterprise have a greater impact on public cultural services supply. And their strategies are practiced in two ways, namely supply and not to supply. Here, set the condition as the government provides public cultural services and companies do not. Government benefit is $R_{1}$, the benefit of the enterprise is 0 . Conversely, when the enterprise supply and the government do not supply, enterprises benefit is $R_{1}^{\prime}$, the benefit of the government is $R_{2}$. Although the government did not provide public cultural service, the enterprises implement the government's system which supports the government policy. This is useful for the government. When both of the government and enterprises provide public cultural services, government benefit is $R$, companies' benefit is $R^{\prime}$. If both the government and the companies do not supply, then the gain of both sides is 0 .

Table 7. The payoff matrix government and enterprise supplies.

\begin{tabular}{|c|c|c|c|}
\hline \multicolumn{2}{|c|}{} & \multicolumn{2}{c|}{ Enterprise } \\
\cline { 3 - 4 } \multicolumn{2}{|c|}{} & Supply & Not supply \\
\hline \hline \multirow{3}{*}{ Government } & Supply & $R, R^{\prime}$ & $R_{1}, 0$ \\
\cline { 2 - 4 } & Not supply & $R_{2}, R_{1}^{\prime}$ & 0,0 \\
\hline
\end{tabular}

$R>R_{1}>R_{2}$, but $R^{\prime}, R_{1}^{\prime}$ could not be determined. Therefore this paper uses evolutionary game analysis to analyze the actual situation of the government and the enterprise on public cultural service supply, and makes adjustments on their own strategies separately as shown in Table 7. 
Table 8. Partial equilibrium stability.

\begin{tabular}{|c|c|c|c|c|c|}
\hline Equilibrium point $(T, F)$ & \multicolumn{2}{|c|}{$\operatorname{det} Y$} & \multicolumn{2}{|c|}{ Str $Y$} & + \\
\hline \hline$(0,0)$ & $R_{1} \bullet R_{1}^{\prime}$ & + & $R_{1}+R_{1}^{\prime}$ & Instability point \\
\hline \hline$(0,1)$ & $-\left(R-R_{2}\right) \bullet R_{1}^{\prime}$ & - & $R-R_{2}-R_{1}^{\prime}$ & Unknown & Saddle point \\
\hline$(1,0)$ & $-R_{1} \bullet R^{\prime}$ & - & $R^{\prime}-R_{1}$ & Unknown & Saddle point \\
\hline$(1,1)$ & $\left(R-R_{2}\right) \bullet R^{\prime}$ & + & $-\left(R-R_{2}+R^{\prime}\right)$ & - & Saddle point \\
\hline
\end{tabular}

Setting up the government and enterprise to independently and randomly select the strategy of supplying public cultural services or not, and repeated game can be implemented. Therefore, the probability of the government supply is $T$, the probability of not supply is $1-T$; the probability of enterprise supply is $F$, the probability of not supply is $1-F$. According to Malthusian theorem, the growth rate of government policies on selecting supply frequency is $\dot{T} / T$, which should be the difference between fitness $E_{w} W\{f, 1-F\}^{T}$ and the average degree of fitness $\{T, 1-T\} W\{F, 1-F\}^{T}$. When the probability of government supply is 1 , the benefit matrix is:

$W=\left[\begin{array}{cc}R & R_{1} \\ R_{2} & 0\end{array}\right]$

$\dot{T}=T(1-T)\{1,-1\} D\{F, 1-F\}^{T}$

simplified as

$\dot{T}=T(1-T)\left[\left(R-R_{1}-R_{2}\right) F+R_{1}\right]$

Similarly, the growth rate of companies strategies on choosing supply frequency is $\dot{F} / F$. It should be the difference between fitness $E_{J} H\{T, 1-T\}^{T}$ and the average degree of fitness $\{F, 1-F\} H\{T, 1-T\}^{T}$. When the probability of enterprise supply is 1 , the benefit matrix is

$$
\begin{aligned}
& H=\left[\begin{array}{cc}
R^{\prime} & 0 \\
R_{1}^{\prime} & 0
\end{array}\right] \\
& \dot{F}=F(1-F)\{-1,1\} H\left\{t, 1-F^{T}\right\}^{T} \text { simplified as } \\
& \dot{F}=F(1-F)\left[R_{1}^{\prime}+\left(R^{\prime}-R_{1}^{\prime}\right) T\right]
\end{aligned}
$$

According to matrix stability, we analyze the local stability of these equilibrium points, seeking partial derivatives of $\dot{T}$ for $T$, and the partial derivative of $\dot{F}$ for $F$, the matrix is as follows:

$$
\begin{aligned}
& Y=\left[\begin{array}{cc}
\dot{\partial} / \partial T & \dot{\partial} \dot{T} / \partial F \\
\dot{F} / \partial T & \partial \dot{F} / \partial F
\end{array}\right]= \\
& {\left[\begin{array}{cc}
(1-2 T)\left[\left(R-R_{1}-R_{2}\right) F+R_{1}\right] & T(1-T)\left(R-R_{1}-R_{2}\right) \\
F(1-F)\left(R^{\prime}-R_{1}^{\prime}\right) & (1-2 F)\left[R_{1}^{\prime}+\left(R^{\prime}-R_{1}^{\prime}\right) T\right]
\end{array}\right]}
\end{aligned}
$$

There into

$$
\begin{aligned}
& \operatorname{det} Y=(1-2 T)(1-2 F)\left[\left(R-R_{1}-R_{2}\right) F+R_{1}\right] \\
& {\left[R_{1}^{\prime}+\left(R^{\prime}-R_{1}^{\prime}\right) T\right]-T F(1-T)(1-F)\left(R-R_{1}-R_{2}\right)\left(R^{\prime}-R_{1}^{\prime}\right)} \\
& \operatorname{tr} Y=(1-2 T)\left[\left(R-R_{1}-R_{2}\right) F+R_{1}\right] \\
& +(1-2 F)\left[R_{1}^{\prime}+\left(R^{\prime}-R_{1}^{\prime}\right) T\right]
\end{aligned}
$$

Partial equilibrium stability is shown in Table $\mathbf{8}$.

The above table shows that the point $(0,0)$ is unstable; points, $(0,1)$ and $(1,0)$ are saddle points; evolutionary stable point is $(1,1)$. Fig. (3) is a strategy evolution chart

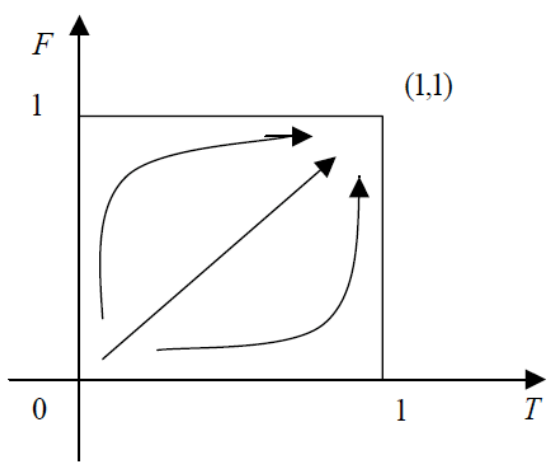

Fig. (3). Strategy evolution chart.

From Fig. (3) we can conclude that the public cultural service supply strategy systems of the government and enterprises evolved from unstable point $(0,0)$ to a stable point $(1,1)$. In consequence, the best way to supply is the government's cooperation with enterprises to provide public cultural services together.

\section{CONCLUSION}

By establishing the AHP model, considering the profits income, policy support, branding and social stability factors affecting the supply of public cultural services, this paper obtained respective proportions of government, enterprise and the third sector in public cultural services supply as follows: the government's is 0.501 , enterprises' is 0.310 and the third sector's is 0.187 . It shows that the government and enterprises supply have greater impact on the supply of public cultural services. Then this paper established that the public cultural service supply strategy systems of the government and enterprises evolved from unstable point to a stable point through the game analysis, and evolutionary game. Therefore, the best way to supply is government and enterprises combined effect to provide public cultural services. 
In order to implement this model, several suggestions have been proposed: first, to encourage the corporate sectors access to public cultural services, to innovate the way of supplying public cultural services; second is to establish and improve taxation system of public cultural services, to use fiscal expenditure, government procurement and tax incentives properly to encourage and guide various types of enterprises and social capital for participating in public cultural service delivery in forms of equity, cooperation, leasing, contracting etc.; third is to build a sound legal framework for public cultural services which needs to learn from the experience of international community. Finally, it needs to establish and complete the legal system of public cultural services.

\section{CONFLICT OF INTEREST}

The authors confirm that this article content has no conflict of interest.

\section{ACKNOWLEDGEMENTS}

Declared none.

\section{REFERENCES}

[1] C. Ying, "Survey on satisfaction degree of demand for the public cultural services in new guangming road of shenzhen city", Journal of Library Work and Study, vol. 35, no. 4, pp. 2-6, 2013.

[2] C. Camarero and M. J. Garrido "Fostering innovation in cultural contexts market orientation, service orientation, and innovations in museums", Journal of Service Research, vol. 1, pp. 39-58, 2012

[3] L. Yanling and Z. Miao, "The satisfaction research of farmers' needs in rural information public services", Journal of Chinese Public Administration, vol. 28, no. 10, pp. 119-123, 2013.

[4] Y. Noh, "A study measuring the performance of electronic resources in academic libraries", Emerald Group Publishing Limited, vol. 2, pp. 134-153, 2012.

[5] S. Liang, "Research on public cultural model in based on an evolutionary game analysis", Luojia Manag Ement Review, vol. 11, no.2, pp. 210-216, 2012

[6] C. H. Tsai, Y. J. Peng and H.H Wu, "Evaluating service process satisfaction of a tourism factory-using brands' health museum as an example", Information Science and Service Science and Data Mining (ISSDM), vol. 6, pp. 244-247, 2012.

[7] W. Wenzhong, "The exploring on the public cultural service extension in digital age", Chinese Market, vol. 51, pp. 129-130, 2014.

[8] Z. Zanmei, "Research on the multi-center governance of public cultural service-based on the analysis of the "N city" practice", $\mathrm{Li}$ brary, vol. 6, pp. 135-137, 2014.

Received: May 26, 2015

Revised: July 14, 2015

Accepted: August 10, 2015

(C) Li et al.; Licensee Bentham Open.

This is an open access article licensed under the terms of the (https://creativecommons.org/licenses/by/4.0/legalcode), which permits unrestricted, noncommercial use, distribution and reproduction in any medium, provided the work is properly cited. 